\title{
De novo dyspareunia after pelvic organ prolapse surgery
}

\author{
Montserrat Espuña $\cdot$ Montserrat Puig • \\ Francisco Carmona
}

Received: 8 December 2009 / Accepted: 6 January 2010 /Published online: 23 February 2010

(C) Springer-Verlag 2010

\begin{abstract}
Dyspareunia is a sexual dysfunction defined as genital pain experienced before, during, or after sexual intercourse. Pain during intercourse is a difficult clinical problem and one of the commonest complaints in gynecological practice. The causes of dyspareunia may be classified as organic, emotional, and psychological. Pelvic organ prolapse (POP) has been considered a cause of dyspareunia and sexual dysfunction may be affected positively or negatively by surgical treatment of prolapse. In this paper, the authors review the de novo dyspareunia after POP surgery. They conclude that the incidence of de novo dyspareunia was higher in series with vaginal repair with synthetic mesh than in abdominal sacropexy.
\end{abstract}

Keywords Pelvic organ prolapse - De novo dyspareunia . Surgery

\section{Dyspareunia and pelvic floor disorders}

Dyspareunia is a sexual dysfunction defined as genital pain experienced before, during, or after sexual intercourse [1]. Some investigations support the consideration of dyspareunia as pain disorders that interfere with sexuality, rather than as sexual disorders characterized by pain [2].

Pain during intercourse is a difficult clinical problem and one of the commonest complaints in gynecological practice.

\footnotetext{
M. Espuña $\cdot$ M. Puig $\cdot$ F. Carmona $(\triangle)$

Service of Gynecology, Institut Clínic de Ginecología,

Obstetricia i Neonatología, Hospital Clínic,

Villarroel 170,

08036 Barcelona, Spain

e-mail: f.carmona@ub.edu
}

In a review of 18 high-quality studies with representative samples of women with coital sexual activity, the prevalence of dyspareunia was reported to be between $8 \%$ and $21 \%$ [3].

Pelvic floor disorders (PFD) include pelvic organ prolapse (POP), urinary incontinence (UI), anal incontinence (AI), and other sensory and emptying abnormalities of the lower urinary and gastrointestinal tracts. According to the first nationwide population-based survey assessing the prevalence of the three major symptomatic PFD in US women, the prevalence of at least one pelvic floor disorder is $23.7 \%$, with $15.7 \%$ of women ( $95 \%$ confidence interval [CI], 13.2-18.2\%) with symptoms of UI, $9.0 \%$ of women (95\% CI, 7.3-10.7\%) experiencing fecal incontinence (FI), and $2.9 \%$ of women $(95 \% \mathrm{CI}, 2.1-3.7 \%)$ with a POP [4].

Pauls et al. [5] studied all new patients with PFD referred to a urogynecology practice with the objective of evaluating sexual function. Over 6 months, 450 new patients were enrolled; sexual activity and function were evaluated by a sexual questionnaire and female sexual function index (FSFI) and sexual function information were obtained during the physician interview. Two hundred forty-three (54\%) of the 460 women included were not sexually active. They estimate a prevalence of sexual complaints in $64 \%$ of sexually active women. In this population in which pelvic support problems occur, sexual changes due to lack of support of pelvic organs are often added to the genital changes for aging (the atrophy) and also to the erectile difficulties in the partners.

In a cohort of community-dwelling women who were enrolled in a managed healthcare plan, it was demonstrated that PFDs do not independently affect sexual activity or satisfaction. Women with $\mathrm{POP}, \mathrm{AI}$, or any $\geq 1 \mathrm{PFD}$, although less likely to be sexually active, had rates of sexual activity equivalent to unaffected women after the data was controlled for confounders. Factors that independently 
associated to decreased sexual activity were: age, menopause, and the lack of sexual desire; increased rates of sexual activity were identified in divorced women or currently treated with sexual hormones. Sexual satisfaction was also significantly lower in patients with any PFD, compared with unaffected women. However, after being controlled for confounding variables, sexual satisfaction was affected negatively only by being menopausal, lack of sexual desire, and having pain with intercourse [6].

\section{Pelvic organ prolapse and dyspareunia}

The causes of dyspareunia may be classified as organic, emotional, and psychological. POP has been considered a cause of dyspareunia [3]. In a study conducted by Sobhgo et al. [7] to determine rate and related factors of dyspareunia, pelvic examinations and connective tissue disorders were investigated, degree of POP was determined by the pelvic prolapse quantification (POPQ) system [8], and stage 0 and 1 were considered as good support. To determine the presence of dyspareunia, all women were asked about the episodes of pain before, during, or after intercourse. Univariate analysis revealed significant relations between POP as a medical condition and dyspareunia $(p<0.04)$ and a significant relation was also found between the symptom of prolapse (feeling a mass in the vagina) and dyspareunia $(p<0.0001)$.

Women with POP may have sexual dysfunction and coital pain due to mechanical obstruction; however, the reasons probably extend beyond the local effects. It has been shown that, in women seeking treatment for advanced prolapse, their body image is decreased and they have lower quality of life scores $[9,10]$.

Sexual dysfunction may be affected positively or negatively by surgical treatment of prolapse. Assuming that the physical effect of prolapse is one of the main contributing factors to having dyspareunia, one could logically assume that an intervention leading to the improvement of POP symptoms should also improve the sexual pain symptom. Surgery is a trauma and healing by surgery involves scar formation in all cases. Pain in surgical incision scars occurs, in a certain percentage, after any type of surgery. Halvorsen and Metz [11] described surgical and traumatic factors as organic causes of dyspareunia and pointed out that hysterectomy and vaginal wall trauma during surgery can induce dyspareunia. The perception of coital pain in women after prolapse surgery may be due to different causes related to the procedure: discomfort in perineal area due to the scar, stenosis of the vagina, mesh erosion, mesh shrinkage, and extensive fibrosis.

In a prospective study of subjects undergoing vaginal surgery for POP, Pauls et al. [12] found no differences in
FSFI domain or total scores between the preoperative and postoperative period. Patients also reported similar degrees of bother because of sexual symptoms on the visual analog scale, reporting a mean of 5 of 10 both before and after surgery. Sexual frequency was also not significantly different. The deterioration in sexual function was likely to occur in women with better sexual function scores preoperatively. What is most interesting in their results is the observation that the symptom of vaginal bulging preoperatively was correlated with FSFI pain score $(r=-0.416, p=0.002)$ and vaginal pain postoperatively was also correlated with FSFI pain score $(r=-0.631$, $p<0.001)$. The complaint of vaginal tightness was cited by $27 \%$ of their patients. The lack of benefit after surgery according to the FSFI domain or total scores between the preoperative and postoperative period may be attributable to postoperative dyspareunia.

A proportion of women, before surgery for POP, will have dyspareunia and, after surgery, this symptom may be resolved, stay at the same level, or get worse. But a group of sexually active patients who never had coital pain before surgery will have de novo dyspareunia after the procedure. Most of the studies about results of prolapse surgery report about rates of dyspareunia after surgery, but information about changes after surgery are less common [13-16]. If we do not have information about the preoperative rate of this symptom, it is impossible to know the impact of a surgical procedure on dyspareunia and also to determine if a postoperative dyspareunia is a complication of the surgery or a persistency of this symptom. There is a need to include this symptom as an outcome measure when we evaluate our results of POP treatments and to identify patients with de novo dyspareunia after surgery and consider it as a postsurgical complication. Moreover, before surgery, the probability of postoperative de novo dyspareunia should be discussed with the patient.

The objective of this review is to analyze the data about prolapse surgery results, specifically the incidence of "de novo dyspareunia" and the relationship between "de novo dyspareunia" and type of surgery.

\section{De novo dyspareunia after vaginal repairs with native tissue}

The traditional vaginal approach to prolapse surgery carries significant low postoperative morbidity, but the anatomical recurrence is higher [17]. The maintenance of sexual function in women with coital sexual activity requires the preservation of a certain vaginal length and caliber adequate for sexual intercourse. The surgical procedure may contribute to altered sexual function following vaginal surgery. Improvements in sexual function following vaginal surgery 
were believed to be due to the cessation of feeling a bulge, whereas worsening sexual function was believed to be caused mainly by dyspareunia. Dyspareunia following vaginal surgery for POP has been reported by many authors $[11,18-22]$ and was often attributed to the posterior colporrhaphy with levator plication and due to narrowing of the vagina $[13,22]$.

Dyspareunia after surgery of posterior compartment

The treatment of rectocele is controversial; most clinicians would repair symptomatic rectocele, but many choose not to treat asymptomatic rectocele because there is little documented benefit to justify the risk of postoperative dyspareunia. Postoperative coital pain has been of significant concern for years with the surgical management of rectocele and perineal body defects. Surgical correction of posterior vaginal wall prolapse and particularly posterior colporrhaphy has been associated with worsening sexual function, specially increasing dyspareunia with some type of surgeries. Weber et al. [13], in a prospective observational study of sexual function after prolapse repairs, found that performance of a posterior colporrhaphy and especially a posterior colporrhaphy with Burch colposuspension were the only variables that predicted postoperative dyspareunia.

Different authors have evaluated the impact on the symptom of dyspareunia with different vaginal procedures to correct posterior vaginal defect (Table 1). Kahn and Stanton [22] retrospectively evaluated the prevalence of dyspareunia before and after posterior colporrhaphy with levator plication in 231 patients; only $18 \%$ had dyspareunia before surgery and $27 \%$ complained of this symptom postoperatively. The rate of de novo dyspareunia was low after traditional posterior colporrhaphy, which is performed by plicating the patient's native rectovaginal connective tissue in the midline or after site-specific posterior colporrhaphy [23-27]. Abramov et al. [28], in a retrospective review, show similar rates of dyspareunia with posterior colporrhaphy and site-specific rectocele repair in spite of higher anatomic recurrence of site-specific rectocele repair. Posterior colporrhaphy with levator plication has been abandoned due to postoperative pain. Transanal repair has been evaluated in a prospective randomized study [29] with 15 women who underwent transanal rectoceleplasty and another 15 who underwent vaginal posterior colporrhaphy; none of the patients reported de novo dyspareunia, but $27 \%$ reported improvement. The transanal technique was associated with more clinically diagnosed recurrences of rectocele and/or enterocele. According to their results, adverse effects on sexual life were avoided by use of both techniques.

Komesu et al. [30], more recently, have published a study with the objective of determining the effect of posterior repair (PR) on sexual function in patients who have undergone incontinence and/or pelvic reconstructive surgery. Participants completed the Pelvic Organ Prolapse/ Urinary Incontinence Sexual Questionnaire (PISQ) before and after the operation. PISQ scores were compared between women who underwent PR and women who did not. Preoperative PISQ scores were similar between groups. After the operation, both groups significantly improved their PISQ scores, without a difference between groups. Although there was no difference in dyspareunia between

Table 1 De novo dyspareunia after posterior vaginal repair (PR) with native tissues

\begin{tabular}{|c|c|c|c|c|c|c|c|}
\hline \multirow[t]{2}{*}{ Author } & \multirow[t]{2}{*}{$n$} & \multirow[t]{2}{*}{ Type of surgery } & \multicolumn{2}{|c|}{ Follow-up } & \multirow{2}{*}{$\begin{array}{l}\text { Stages and compartments } \\
\text { of women with POP }\end{array}$} & \multirow[t]{2}{*}{ Outcome } & \multirow{2}{*}{$\begin{array}{l}\text { De novo } \\
\text { dyspareunia (\%) }\end{array}$} \\
\hline & & & Months & Percent & & & \\
\hline Kahn (1997) & 231 & $\begin{array}{l}\text { Posterior } \\
\text { colporrhaphy } \\
\text { and levator plication }\end{array}$ & 42.5 & 74 & Rectocele & History, symptoms, & $\begin{array}{l}\text { Sexual dysfunction } \\
(18 \% \text { vs } 27 \%) \\
\text { increased }\end{array}$ \\
\hline $\begin{array}{l}\text { Glavind } \\
(2000)\end{array}$ & 67 & $\begin{array}{l}\text { Site-specific fascia } \\
\text { repair }\end{array}$ & 3 & n.a. & Rectocele & History, symptoms, & 3 \\
\hline Porter (1999) & 89 & $\begin{array}{l}\text { Site-specific fascia } \\
\text { repair }\end{array}$ & 6 & 82 & Rectocele & History, symptoms, & 3 \\
\hline Sardeli (2007) & 51 & $\begin{array}{l}\text { Site-specific fascia } \\
\text { repair }\end{array}$ & 26.7 & & $\begin{array}{l}\text { Stage } 2 \text { or greater than } \\
\text { posterior vaginal wall } \\
\text { prolapse }\end{array}$ & $\begin{array}{l}\text { History, symptoms, } \\
\text { questionnaires }\end{array}$ & 2 \\
\hline Oom (2008) & 33 & $\begin{array}{l}\text { Anterolateral } \\
\text { rectopexy }\end{array}$ & 74 & 92 & $\begin{array}{l}\text { Symptomatic rectocele } \\
(\text { depth }>3 \mathrm{~cm})\end{array}$ & Symptoms, questionnaires & 0 \\
\hline $\begin{array}{l}\text { Abramov }^{\mathrm{a}} \\
(2005)\end{array}$ & $\begin{array}{l}182 \\
\text { vs } \\
124\end{array}$ & $\begin{array}{l}\text { Posterior } \\
\text { colporrhaphy } \\
\text { vs site-specific } \\
\text { fascia repair }\end{array}$ & 12 & 83 & $\begin{array}{l}\text { Advanced posterior } \\
\text { vaginal prolapse }\end{array}$ & $\begin{array}{l}\text { History, symptoms, } \\
\text { questionnaires }\end{array}$ & $\begin{array}{l}11 \\
11\end{array}$ \\
\hline
\end{tabular}

${ }^{\mathrm{a}}$ Comparative retrospective 
groups preoperatively, dyspareunia prevalence postoperatively was significantly lower in the women with no PR and increased in the PR group. In this study, we can observe the importance of drawing a distinction between the evaluation of overall sexual function and individual parameters.

\section{Dyspareunia after surgery of anterior compartment}

The sensitivity of the anterior vaginal wall may be altered by the creation of scars and surgery in this area might be a cause of dyspareunia. Vaginal innervation is concentrated on anterior and distal aspects of the vaginal wall and it may be affected by operations for cystocele and UI. Considering that the "G-spot", which is a supersensitive area for some women, is placed on the anterior vaginal wall [31], sexual function may also be altered by scars in this area. The surgical management of cystocele remains problematic with a plethora of surgical options available to the clinician. Maher and Baessler [32] published a review of the literature to provide an evidence-based approach to the surgical management of anterior vaginal compartment prolapse; no data about de novo dyspareunia after anterior repair was published in this review. In the Cochrane review of surgical operations for POP, of the 11 randomized controlled trials (RCTs) or quasirandomized controlled trials of surgical procedures to treat anterior vaginal wall prolapse, dyspareunia was analyzed as an outcome in only one [33].

\section{Dyspareunia after vaginal repair for apical prolapse}

Restoration of apical support can be carried out through vaginal or abdominal approaches. Traditional vaginal repair for apical prolapse with native tissues includes: sacrospinous ligament suspension, uterosacral ligament suspension, and McCall's culdoplasty.

The main indication for sacrospinous ligament suspension is to correct total procidentia, a posthysterectomy vaginal vault prolapse, or a posthysterectomy enterocele. The operation is effective for anatomic correction but does distort the vaginal axis. Because of the distorted vaginal axis, dyspareunia is a possible postoperative complication after sacrospinous fixation and, generally, is an operation considered for the sexually less active patient [34]. De novo dyspareunia after sacrospinous ligament fixation has been evaluated in a few publications. Nieminen et al. [34, 35] evaluated 122 cases of unilateral sacrospinous ligament fixation and 33 were sexually active with a median length of follow-up of 24 months; the rate of reported dyspareunia was $9 \%$ (three out of 33 ). In a recent publication by Baumann et al. [36], 52 patients were examined during a follow-up period of 38 months and only three $(6 \%)$ patients experienced de novo dyspareunia, which resolved in two cases after stitch removal. After bilateral sacrospinous ligament fixation in a group of 51 women, three of 19 $(15.8 \%)$ women reported dyspareunia postoperatively, but the authors attributed the postoperative de novo dyspareunia to their concomitant perineorrhaphy.

High uterosacral vault suspension for POP has been evaluated by Silva et al. [37] in 110 patients with a mean follow-up period of 5.1 years. Vaginal hysterectomy was performed in $37.5 \%$ of the patients, while anterior colporrhaphy, posterior colporrhaphy, and suburethral slings were performed in $58.3 \%, 87.5 \%$, and $31.9 \%$, respectively. Analysis of the 34 people that were sexually active both preoperatively and postoperatively shows that seven cases (20\%) of postoperative dyspareunia occurred de novo. The reasons related to surgery cited by the patients were: tight introitus, vaginal constriction, and recurrent symptomatic prolapse. Of the 31 who responded to the satisfaction domain of the FSFI, 94\% (29 out of 31) reported normal satisfaction. Four of the seven patients with de novo dyspareunia reported normal satisfaction.

\section{De novo dyspareunia after vaginal repairs with mesh}

Multiple biologic and synthetic materials have been introduced to complement, reinforce, or replace native tissue in reconstructive surgical procedures. In the last 5 years, publications with results on the use of graft materials in prolapse surgery have increased, reflecting the change in surgical procedures. Theoretically, the objective of this change is to improve anatomic outcomes of transvaginal prolapse repairs and decrease the reoperation rate for recurrence of prolapse with native tissues. The positive impact in functional aspects of the low urinary tract are demonstrated and also improvement in a global evaluation of sexual function measured with specific questionnaires, but in most of these publications, de novo dyspareunia is not reported as a postoperative complication.

We found only four studies reporting about de novo dyspareunia after the use of biologic graft (Table 2). In noncomparative studies, the rates of this postoperative complication after biological mesh ranges from $0 \%$ to $11 \%$ [38-41].

The data available from RCTs comparing the use of biological grafts with standard repair techniques show that, at a period of 1 year postoperative, there was no increase in the risk of dyspareunia. Meschia et al. [40], in a prospective, randomized, multicenter trial in 206 women with stage II or greater anterior vaginal wall prolapse randomly assigned to undergo anterior vaginal repair or the same procedure with Pelvicol implant reinforcement, did not report differences in rates of de novo dyspareunia.

Paraiso et al. [41], in a randomized trial of three surgical techniques including biological graft augmentation for recto- 


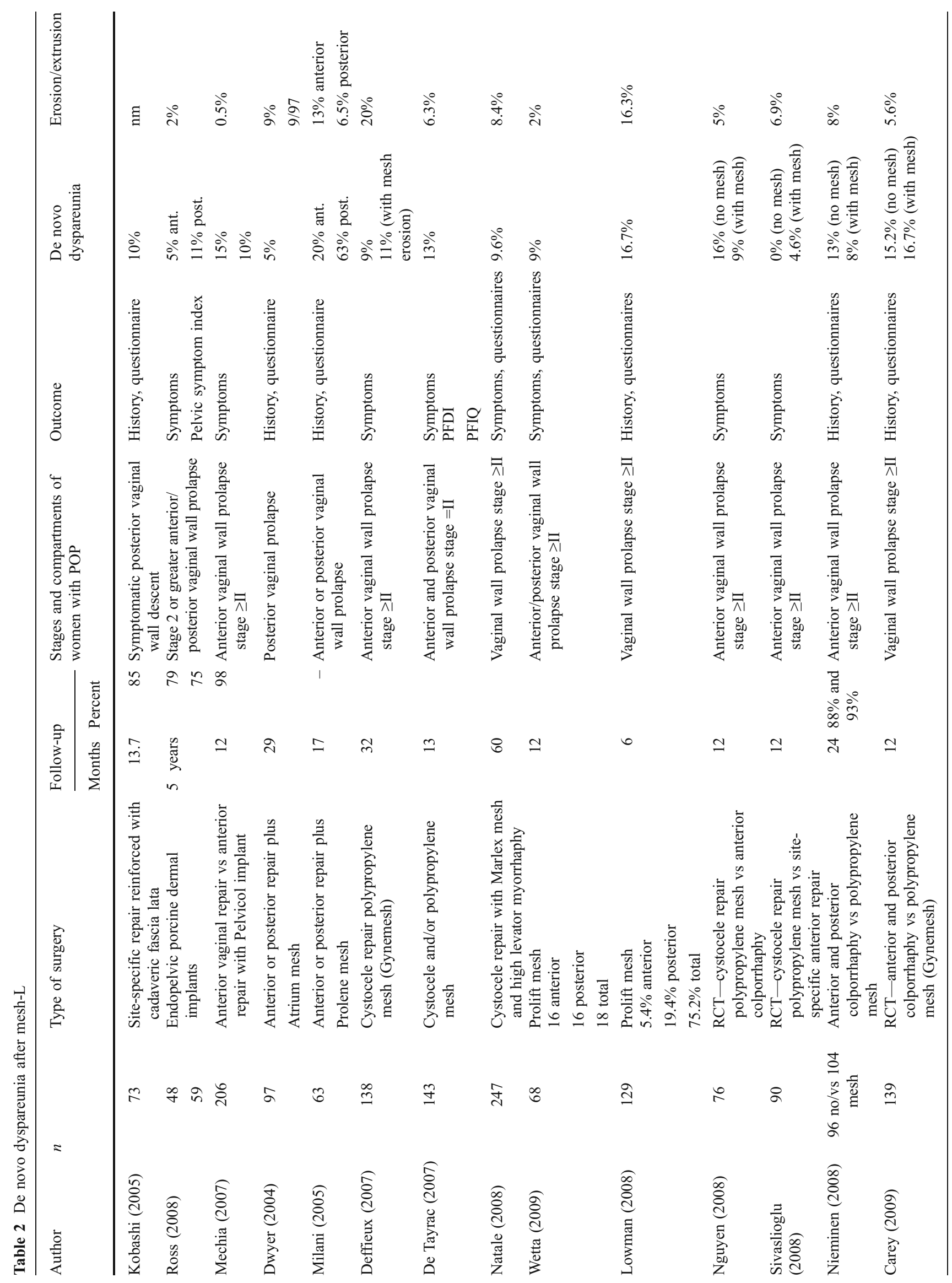


cele repair, studied 106 women with stage II or greater posterior vaginal wall prolapse who were randomly assigned to posterior colporrhaphy $(n=37)$, site-specific rectocele repair $(n=37)$, or site-specific rectocele repair augmented with a porcine small intestinal submucosa graft. There was no significant change in the rate of dyspareunia 1 year after surgery and there were no differences between groups. Overall sexual function as measured by the Pelvic Organ Prolapse/Urinary Incontinence Sexual Questionnaire Short Form (PISQ-12) improved significantly in all groups postoperatively $(p<0.001)$, with no differences between groups.

Dyspareunia after vaginal repair with synthetic mesh implant may be caused by mesh erosion, mesh shrinkage, and extensive fibrosis and the problem might be because of the characteristics of the graft as well as the technique used for insertion. De novo dyspareunia rates after transvaginal repair with nonabsorbable graft ranges from $5 \%$ to $60 \%$ [42-48] (Table 2). The highest rate was reported by Milani et al. [43] after PR with polypropylene mesh in which the symptom of dyspareunia changed from $6 \%$ preoperatively to $69 \%$ postoperatively. However, when Dwyer et al. [42] analyzed the effect of surgery for the posterior vaginal defect with Atrium Polypropylene on the preoperative and postoperative symptoms of dyspareunia, the prevalence of this symptom was $26 \%$ preoperatively and decreased to $9 \%$ after surgery.

With the purpose to determine exactly the incidence of de novo dyspareunia after a vaginal procedure with a vaginal mesh (Prolift), Lowman et al. [47] analyzed the evolution of patients with preoperative dyspareunia and classified them according to: resolution, improvement, persistency, get worse, and unknown and patients without dyspareunia preoperatively were followed up and classified as: no dyspareunia and dyspareunia de novo. There were 57 sexually active patients included in the study (47 were sexually active before surgery, 10 became sexually active after surgery). Twenty-one patients had dyspareunia before surgery and 36 patients who did not have pain with intercourse before surgery, six of these 36 developed pain with intercourse after surgery. The de novo dyspareunia rate was $16.7 \%$.

RCTs that have been published comparing surgery with synthetic mesh implant and other procedures reported a few data about dyspareunia [49-51] and we could find information about de novo dyspareunia in only two. Nguyen and Burchette [50] published a RCT evaluating 76 women to either anterior colporrhaphy or mesh kit repair (Perigee propylene mesh). There was no difference in postoperative dyspareunia in both groups, the rates of de novo dyspareunia were $16 \%$ (four of 26 patients) and $9 \%$ (two of 23 patients) in the colporrhaphy and mesh groups, respectively. PISQ-12 scores did not change significantly postoperatively. In another randomized comparison of polypropylene mesh surgery with site-specific surgery for the treatment of cystocele [51], de novo dyspareunia was observed in two patients $(4.6 \%)$ in the mesh surgery group and no dyspareunia was seen in the site-specific surgery group.

\section{De novo dyspareunia after abdominal surgery for POP}

The benefits of transabdominal approaches for the repair of an apical prolapse include a more reliable fixation of the vaginal apex, with minimal changes in the vaginal anatomy. Abdominal sacrocolpopexy (ASC) is the most common transabdominal procedure, indicated traditionally for vaginal vault prolapse in women with a shortened narrowed vagina due to prior surgeries and with the desire to have coital activity. Outcome data for ASC support the efficacy of the technique supporting the vaginal apex, but sparse data reported about postoperative de novo dyspareunia. In a comprehensive review of Nygaard et al. [52], only 23 of the 48 studies reviewed report some information about dyspareunia after surgery and more than $50 \%$ of these 23 studies reported "no any difficulty with coitus." In a prospective randomized trial comparing sacrocolpopexy to bilateral sacrospinous suspension, Benson et al. [53] reported a

Table 3 De novo dyspareunia after LSC

\begin{tabular}{|c|c|c|c|c|c|c|c|c|}
\hline \multirow[t]{2}{*}{ Author } & \multirow[t]{2}{*}{$n$} & \multirow[t]{2}{*}{ Type of surgery } & \multicolumn{2}{|c|}{ Follow-up } & \multirow{2}{*}{$\begin{array}{l}\text { Stages and compartments } \\
\text { of women with POP }\end{array}$} & \multirow[t]{2}{*}{ Outcome } & \multirow{2}{*}{$\begin{array}{l}\text { De novo } \\
\text { dyspareunia } \\
(\%)\end{array}$} & \multirow{2}{*}{$\begin{array}{l}\text { Erosion } \\
(\%)\end{array}$} \\
\hline & & & Months & Percent & & & & \\
\hline North (2009) & 22 & LSC & 26.5 & 100 & Vaginal vault prolapse & Symptoms/questionnaires & 0 & 5 \\
\hline Claerhout (2009) & 132 & LSC & 12.5 & 92 & Vaginal vault prolapse & Symptoms/questionnaires & 19 & 4.5 \\
\hline Sarlos (2008) & 135 & $\begin{array}{l}\text { Supracervical } \\
\text { hysterectomy }+ \text { LSCP } \\
56 \text { only LSCP }\end{array}$ & 12 & 75 & $\begin{array}{l}55 \text { uterine prolapse and } \\
56 \text { vault prolapse }\end{array}$ & $\begin{array}{l}\text { Symptoms/questionnaires } \\
\text { King's health }\end{array}$ & 1 & 1 \\
\hline Rivore (2007) & 131 & LSC & 33 & 95 & $\begin{array}{l}\text { Genital prolapse stage } \\
3 \text { or } 4\end{array}$ & History/symptoms & 0 & 5 \\
\hline Rozet (2005) & 363 & LSC & 14.6 & 90 & $\begin{array}{l}\text { Genital prolapse stage } \\
2,3 \text {, and } 4\end{array}$ & Symptoms/questionnaires & 0 & $<1$ \\
\hline
\end{tabular}


$58 \%$ rate of postoperative dyspareunia after sacrospinous suspension and no dyspareunia after sacrocolpopexy. However, women undergoing vaginal surgery had numerous concomitant procedures. We can estimate that the rate of de novo dyspareunia after ASC ranges from $0 \%$ to $10 \%$.

In more recent years, laparoscopic sacrocolpopexy (LSC) is performed also in multicompartment POP in young women, the rational for this indication is that, for young and sexually active woman with symptomatic POP, sacrocolpopexy with mesh provides anatomic pelvic restoration, durable results, and theoretically less dyspareunia by maintaining vaginal length and axis. Considering that the LSC and the ASC are the same surgical procedure for POP, the results might be comparable when we analyze the rate of de novo dyspareunia.

The largest, prospective, single-center cohort study published until now [54] about 132 consecutive women with vaginal vault prolapse undergoing LSC reported on a rate of de novo dyspareunia of $19 \%$ and $33 \%$ of the 132 women who complained postoperatively of vaginal symptoms that interfered with sexual activity. This percentage is much higher than other three retrospective series published [55-57] (Table 3). North et al. [58], in a prospective study of 22 patients undergoing LSC, reported that, at 2 years follow-up, no women reported new onset of dyspareunia after surgery; in this study, women were asked at each clinic visit whether they were sexually active and, if so, whether they had any coital difficulties including dyspareunia and hispareunia, with this information they could separate the rates of pre, post, and de novo dyspareunia. The differences in these three series can be explained by differences in age and number of patients with preoperative sexual impairment. However, Claerhout et al. [54], in their article, discuss that a more extensive dissection and lateral mesh fixation may also have increased the risk for dyspareunia.

Overall, few series reported sexual function outcomes after ASC or LSC and, in most of them, de novo dyspareunia after abdominal surgery has a low rate. We can consider that sacrocolpopexy with mesh (ASC or LSC) provides anatomic pelvic restoration that favors these low rates of incidental cases of de novo dyspareunia, but differences in the procedure may explain also the differences reported of this postoperative complication. There is need for long-term, prospective RCTs comparing LSC and ASC and analyzing the differences in the procedures.

\section{De novo dyspareunia as a postoperative complication of prolapse surgery}

Surgical trials should make attempts to list minor and severe complications and provide as much detail regarding any interventions needed to manage those complications.
Few studies recorded de novo dyspareunia as a postoperative complication. In general, the incidence of de novo dyspareunia after surgery is low, but the range is very wide. However, sexual function was well-documented preoperatively and postoperatively in $<50 \%$ of the series published with results of vaginal or abdominal procedures for prolapse.

Preoperatively and postoperatively, we must know if women are sexually active and, if so, whether they had any coital difficulties including dyspareunia. During the period of follow-up, questions regarding sexual function need to be asked at each clinic visit, and it cannot be assumed that just because a woman is not sexually active preoperatively that she will remain so after surgery. De novo dyspareunia and dyspareunia must be registered as a complication. We have to consider that participation in sexual activity may change, with women reporting different answers to questions regarding their sexual activity at each visit, reflecting changing relationships or the variable health of their partner, which is known to be a major determinant in whether women with prolapse are sexually active $[5,6]$.

\section{Conclusions}

Sexual health is an important part of our patients' life. Sexual activity and function may be affected by PFD.

POP surgery has, in general, a positive impact on global sexual function. Satisfaction in most patients may be due to complete relief of feeling a vaginal bulge, improving selfimage, and absence of pain.

Coital pain after surgery of POP is frequent complication in sexually active women with coital activity. In this review, we found that the incidence de novo dyspareunia was higher in a series with vaginal repair with synthetic mesh than in abdominal sacropexy.

In women with coital sexual activity and good sexual life before surgery, de novo dyspareunia is an important factor for postoperative deterioration in sexual function.

There is need for long-term, prospective RCTs comparing LSC, ASC, and vaginal prolapse repair. Dyspareunia has to be considered as another outcome measure and must be investigated before and after surgery.

Conflict of interest There is no actual or potential conflict of interest in relation to this article.

\section{References}

1. Basson R, Leiblum S, Brotto L et al (2003) Definitions of women's sexual dysfunction reconsidered: advocating expansion and revision. J Psychosom Obstet Gynaecol 24:221-229 
2. Binik Y, Reissing E, Pukall C, Flory N, Payne K, Khalife S (2002) The female sexual pain disorders: genital pain or sexual dysfunction. Arch Sex Behav 31:425-429

3. Latthe P, Latthe M, Say L, Gulmezoglu M, Khan KS (2006) WHO systematic review of prevalence of chronic pelvic pain: a neglected reproductive health morbidity. BMC Public Health 6:177-183

4. Nygaard I, Barber MD, Burgio KL, Kenton K, Meikle S, Schaffer J, Spino C, Whitehead WE, Wu J, Brody DJ (2008) Pelvic floor disorders network. Prevalence of symptomatic pelvic floor disorders in US women. JAMA 300:1311-1316

5. Pauls RN, Segal JL, Silva WA, Kleeman SD, Karram MM (2006) Sexual function in patients presenting to a urogynecology practice. Int Urogynecol J Pelvic Floor Dysfunct 17:576-580

6. Lukacz ES, Whitcomb EL, Lawrence JM, Nager CW, Contreras R, Luber KM (2007) Are sexual activity and satisfaction affected by pelvic floor disorders? Analysis of a community-based survey. Am J Obstet Gynecol 197:88

7. Sobhgol SS, Alizadeli Charndabee SM (2007) Rate and related factors of dyspareunia in reproductive age women: a crosssectional study. Int J Impot Res 19:88-94

8. Bump RC, Mattiasson A, Bo K (1996) The standardization of terminology of female pelvic organs prolapse and pelvic floor dysfunction. Am J Obstet Gynecol 175:10-17

9. Jelovsek JE, Barber MD (2006) Women seeking treatment for advanced pelvic organ prolapse have decreased body image and quality of life. Am J Obstet Gynecol 194:1455-1461

10. Lowenstein L, Gamble T, Sanses TV, van Raalte H, Carberry C, Jakus S, Kambiss S, McAchran S, Pham T, Aschkenazi S, Hoskey K, Kenton K (2009) Sexual function is related to body image perception in women with pelvic organ prolapse. J Sex Med 6:2286-2291

11. Halvorsen JG, Metz ME (1992) Sexual dysfunction, part 1: classification, etiology and pathogenesis. J Am Board Fam Prac 5:51-61

12. Pauls RN, Silva WA, Rooney CM, Siddighi S, Kleeman SD, Dryfhout V, Karram MM (2007) Sexual function after vaginal surgery for pelvic organ prolapse and urinary incontinence. Am J Obstet Gynecol 197:622-628

13. Weber M, Walters M, Piedmonte M (2000) Sexual function and vaginal anatomy in women before and after surgery for pelvic organ prolapse and urinary incontinence. Am J Obstet Gynecol 182:1610-1615

14. Maher C, Qatawneh A, Dwyer P, Carey M, Cornish A, Schluter P (2004) Abdominal sacral colpopexy or vaginal sacrospinous colpopexy for vaginal vault prolapse: a prospective randomized study. Am J Obstet Gynecol 190:20-26

15. Handa V, Zyczynski H, Brubaker L (2007) Sexual function before and after sacrocolpopexy for pelvic organ prolapse. Am J Obstet Gynecol 197:629-635

16. David-Montefiore E, Barranger E, Dubernard G, Nizard V, Antoine JM, Darai E (2007) Functional results and quality-oflife after bilateral sacrospinous ligament fixation for genital prolapse. Eur J Obstet Gynecol Reprod Biol 132:209-213

17. Maher C, Baessler K, Glazener CM, Adams EJ, Hagen S (2008) Surgical management of pelvic organ prolapse in women: a short version Cochrane review. Neurourol Urodyn 27:3-12

18. Tunuguntla H, Gousse A (2004) Female sexual dysfunction following vaginal surgery: myth or reality? Curr Urol Rep 5:403-411

19. Helstrom L, Nilsson B (2005) Impact of vaginal surgery on sexuality and quality of life in women with urinary incontinence or genital descensus. Acta Obstet Gynecol Scand 84:79-84

20. Holley VR, Gleason B, Apffel L, Scott S (1996) Sexual function after sacrospinous ligament fixation for vaginal vault prolapse. J Reprod Med 41:355-358
21. Colombo M, Milani R (1998) Sacrospinous ligament fixation and modified McCall culdoplasty during vaginal hysterectomy for advanced uterovaginal prolapse. Am J Obstet Gynecol 179:13-20

22. Kahn M, Stanton S (1997) Posterior colporrhaphy: its effects on bowel and sexual function. Br J Obstet Gynaecol 104:82-86

23. Cundiff GW, Weidner AC, Visco AG, Addison WA, Bump RC (1998) An anatomic and functional assessment of the discrete defect rectocele repair. Am J Obstet Gynecol 179:1451-1456

24. Glavind K, Madsen H (2000) A prospective study of the discrete fascial defect rectocele repair. Acta Obstet Gynecol Scand 79:145-147

25. Porter W, Steele A, Walsh P, Kohli N, Karram M (1999) The anatomic and functional outcomes of defect-specific rectocele repairs. Am J Obstet Gynecol 181:1353-1358

26. Sardeli C, Axelsen S, Kjaer D, Bek K (2007) Outcome of site-specific fascia repair for rectocele. Acta Obstet Gynecol Scand 86:973-977

27. Oom D, Gosselink M, van Wijk J, van Dijl V, Schouten W (2008) Rectocele repair by anterolateral rectopexy: long-term functional outcome. Colorectal Dis 10:925-930

28. Abramov Y, Gandhi S, Goldberg R, Botros S, Kwon C, Sand P (2005) Site-specific rectocele repair compared with standard posterior colporrhaphy. Obstet Gynecol 105:314-318

29. Nieminen K, Hiltunen K, Laitinen J, Oksala J, Heinonen PK (2004) Transanal or vaginal approach to rectocele repair: a prospective, randomized. Dis Colon Rectum 47:1636-1642

30. Komesu Y, Rogers R, Kammerer-Doak D, Barber M, Olsen A (2007) Posterior repair and sexual function. Am J Obstet Gynecol 197:101-107

31. Hines T (2001) The G-Spot: a modern gynaecologic myth. Am J Obstet Gynecol 185:359-362

32. Maher C, Baessler K (2006) Surgical management of anterior vaginal wall prolapse: an evidencebased literature review. Int Urogynecol J Pelvic Floor Dysfunct 17:195-201

33. Maher C, Baessler K, Glazener CM, Adams EJ, Hagen S (2007) Surgical management of pelvic organ prolapse in women. Cochrane Database Syst Rev 18(3):CD004014

34. Nieminen K, Heinonen P (2001) Sacrospinous ligament fixation for massive genital prolapse in women aged over 80 years. BJOG 108:817-821

35. Nieminen K, Huhtala H, Heinonen P (2003) Anatomic and functional assessment and risk factors of recurrent prolapse after vaginal sacrospinous fixation. Acta Obstet Gynecol Scand $82: 471-478$

36. Baumann M, Salvisberg C, Mueller M, Kuhn A (2009) Sexual function after sacrospinous fixation for vaginal vault prolapse: bad or mad? Surg Endosc 23:1013-1017

37. Silva W, Pauls R, Segal J, Rooney C, Kleeman S, Karram M (2006) Uterosacral ligament vault suspension: five-year outcomes. Obstet Gynecol 108:255-263

38. Kobashi K, Leach G, Frederick R, Kuznetsov D, Hsiao K (2005) Initial experience with rectocele repair using nonfrozen cadaveric fascia lata interposition. Urology 66:1203-1207

39. Ross J (2008) Porcine dermal hammock for repair of anterior and posterior vaginal wall prolapse: 5-year outcome. J Minim Invasive Gynecol 15:459-465

40. Paraiso MF, Barber MD, Muir TW, Walters MD (2006) Rectocele repair: a randomized trial of three surgical techniques including graft augmentation. Am J Obstet Gynecol 195(6):1762-1771

41. Meschia M, Pifarotti P, Bernasconi F et al (2007) Porcine skin collagen implants to prevent anterior vaginal wall prolapse recurrence: a multicenter, randomized study. J Urol 177:192195

42. Dwyer PL, O'Reilly BA (2004) Transvaginal repair of anterior and posterior compartment prolapse with Atrium polypropylene mesh. BJOG 111:831-836 
43. Milani R, Salvatore S, Soligo M, Pifarotti P, Meschia M, Cortese M (2005) Functional and anatomical outcome of anterior and posterior vaginal prolapse repair with prolene mesh. BJOG 112:107-111

44. Deffieux X, de Tayrac R, Huel C et al (2007) Vaginal mesh erosion after transvaginal repair of cystocele using Gynemesh or Gynemesh-Soft in 138 women: a comparative study. Int Urogynecol J Pelvic Floor Dysfunct 18:73-79

45. De Tayrac R, Devoldere G, Renaudie J, Villard P, Guibaud O, Eglin G (2007) Prolapse repair by vaginal route using a new protected low-weight polypropylene mesh: 1-year functional and anatomical outcome in a prospective multicentre study. Int Urogynecol J 18:251-256

46. Natale F, La Penna C, Padoa A, Panei M, Cervigni M (2008) High levator myorrhaphy for transvaginal suspension of the vaginal apex: long-term results. J Urol 180(5):2047-2052

47. Lowman JK, Jones LA, Woodman PJ, Hale DS (2008) Does the Prolift system cause dyspareunia? Am J Obstet Gynecol 199:707e1-707e16

48. Wetta LA, Gerten KA, Wheeler TL 2nd, Holley RL, Varner RE, Richter HE (2009) Synthetic graft use in vaginal prolapse surgery: objective and subjective outcomes. Int Urogynecol J Pelvic Floor Dysfunct 20(11):1307-1312

49. Sand PK, Koduri S, Lobel RW et al (2001) Prospective randomized trial of polyglactin 910 mesh to prevent recurrence of cystoceles and rectoceles. Am J Obstet Gynecol 184:1357-1362

50. Nguyen JN, Burchette RJ (2008) Outcome after anterior vaginal prolapse repair: a randomized controlled trial. Obstet Gynecol 111:891-898

51. Sivaslioglu AA, Unlubilgin E, Dolen I (2008) A randomized comparison of polypropylene mesh surgery with site-specific surgery in the treatment of cystocoele. Int Urogynecol J Pelvic Floor Dysfunct 19:467-471

52. Nygaard IE, McCreery R, Brubaker L et al (2004) Abdominal sacrocolpopexy: a comprehensive review. Obstet Gynecol 104:805-823

53. Benson JT, Lucente V, McClellan E (1996) Vaginal versus abdominal reconstructive surgery for the treatment of pelvic support defects: a prospective randomized study with long-term outcome evaluation. Am J Obstet Gynecol 175:1418

54. Claerhout F, Roovers JP, Lewi P, Verguts J, De Ridder D, Deprest J (2009) Medium-term anatomic and functional results of laparoscopic sacrocolpopexy beyond the learning curve. Int Urogynecol J Pelvic Floor Dysfunct 20:1119-1125

55. Rozet F, Mandron E, Arroyo C, Andrews H, Cathelineau X, Mombet A, Cathala N, Vallancien G (2005) Laparoscopic sacral colpopexy approach for genito-urinary prolapse: experience with 363 cases. Eur Urol 47:230-236

56. Rivoire C, Botchorishvili R, Canis M, Jardon K, Rabischong B, Wattiez A, Mage G (2007) Complete laparoscopic treatment of genital prolapse with meshes including vaginal promontofixation and anterior repair: A series of 138 patients. J Minim Invasive Gynecol 14:712-718

57. Sarlos D, Brandner S, Kots L, Gygax N, Schaer G (2008) Laparoscopic sacrocolpopexy for uterine and post-hysterectomy prolapse: anatomical results, quality of life and perioperative outcome-a prospective study with 101 cases. Int Urogynecol J Pelvic Floor Dysfunct 19:1415-1422

58. North CE, Ali-Ross NS, Smith AR, Reid FM (2009) A prospective study of laparoscopic sacrocolpopexy for the management of pelvic organ prolapse. BJOG 116:1251-1257 